\title{
Intrapartum cardiotocography and its correlation with umbilical cord blood pH in term pregnancies: a prospective study
}

\author{
Chandrima Ray*, Alokananda Ray
}

Department of Obstetrics and Gynecology, Tata Main Hospital, Jamshedpur, Jharkhand, India

Received: 18 May 2017

Accepted: 24 May 2017

*Correspondence:

Dr. Chandrima Ray,

E-mail: chandrima.ray2012@gmail.com

Copyright: ( ) the author(s), publisher and licensee Medip Academy. This is an open-access article distributed under the terms of the Creative Commons Attribution Non-Commercial License, which permits unrestricted non-commercial use, distribution, and reproduction in any medium, provided the original work is properly cited.

\section{ABSTRACT}

Background: The purpose of intra-partum fetal monitoring is to identify early signs of developing hypoxia. Electronic fetal monitoring is performed using cardiotocograph, which is a paper record of the fetal heart rate (FHR) patterns plotted simultaneously in relation to uterine activity. In low resource settings umbilical cord artery blood gas analysis can provide important information about the foetuses exposed to intrapartum hypoxaemic events and can distinguish the infant at high risk for asphyxia and related sequelae. The aim of this study was to correlate intrapartum CTG findings with umbilical cord blood $\mathrm{pH}$ at birth in term pregnancies in labour and thus evaluate the success of CTG in predicting fetal acidosis during labour.

Methods: The present study included 301 consecutive women with term singleton pregnancies in labour. Intrapartum CTG was taken and classified into normal (category I trace), indeterminate (category II trace) and abnormal (category III trace) according to NICHD 2008 Classification (Adapted by ACOG 2013). Umbilical cord arterial blood was taken immediately after birth, in a pre-heparinised syringe and sent to the laboratory for $\mathrm{pH}$ study to detect acidosis. Cord blood $\mathrm{pH}<7.2$ was taken as acidosis and cord blood $\mathrm{pH} \geq 7.2$ was taken as normal.

Results: In this study, 50.2\% of the women had normal CTG, 36.5\% had indeterminate CTG and $13.3 \%$ had abnormal CTG. $18.3 \%$ of the babies had acidosis. Out of the subjects with abnormal intrapartum CTG, 52.5\% had acidosis, of the subjects with normal intrapartum CTG trace, 7.3\% had acidosis and of the 110 subjects with indeterminate intrapartum CTG, 22.7\% had acidosis. A statistically significant association was found between intrapartum CTG and umbilical cord arterial $\mathrm{pH}(\mathrm{p}<0.001)$.

Conclusions: From the analysis of this study, it can be concluded that an abnormal CTG should be managed appropriately, without delay, in order to prevent acidosis in the neonate and adverse long-term sequelae. The obstetrician should be more vigilant in cases of indeterminate CTG tracings and monitor such labours closely.

Keywords: Acidosis, Cardiotocography, Cord blood pH, Intrapartum fetal monitoring

\section{INTRODUCTION}

Fetal monitoring in labour has witnessed great technological advances: this has partly been driven by increasing number of litigations, majority of them for perinatal deaths pointing to intra-partum causes. Fetal monitoring in labour can be done by intermittent auscultation, electronic fetal monitoring, along with adjuncts to electronic fetal monitoring like fetal scalp stimulation test, fetal scalp blood sampling, fetal pulse oximetry and fetal ST analysis. Electronic fetal monitoring is performed using a cardiotocograph, which is a paper record of the fetal heart rate (FHR) patterns plotted simultaneously in relation to uterine activity. This may be done continuously or intermittently depending upon the facilities available in the labour unit. The purpose of intra-partum fetal monitoring is to identify early signs of developing hypoxia. An essential criterion 
to define an acute intrapartum hypoxic event is evidence of metabolic acidosis in intrapartum fetal blood, umbilical cord or very early neonatal blood samples. ${ }^{1}$ In low resource settings umbilical cord artery blood gas analysis can provide important information about the foetuses exposed to intrapartum hypoxaemic events and can distinguish the infant at high risk for asphyxia and related sequelae. The aim of this study is to correlate intrapartum CTG findings with umbilical cord blood $\mathrm{pH}$ at birth in term pregnancies and thus evaluate the success of CTG in predicting fetal acidosis during labour.

Aim of the study was to correlate intrapartum CTG findings with umbilical cord blood $\mathrm{pH}$ at birth in term pregnancies.

\section{METHODS}

The present study included 301 consecutive women with term singleton pregnancies in labour, who were admitted for delivery in the labour ward at Tata Main Hospital, which is a 940-bedded teaching hospital, attached to Tata Steel in Jamshedpur, Jharkhand. This hospital-based prospective observational study was conducted over a period of 12 months from $1 / 11 / 2014$ to $31 / 10 / 2015$.

Intrapartum CTG tracing was taken and classified into Normal (category I trace), Indeterminate (category II trace) and Abnormal (category III trace) according to NICHD 2008 Classification (Adapted by ACOG 2013). 2,3 Umbilical cord arterial blood was taken immediately after birth, in a pre-heparinised syringe and sent to the laboratory for $\mathrm{pH}$ study to detect acidosis. Cord blood $\mathrm{pH}$ $<7.2$ was interpreted as acidosis and cord blood $\mathrm{pH} \geq 7.2$ as normal.

Sample size for the study was calculated as:

$\mathrm{n}=\mathrm{Z}^{2} \times(\mathrm{p}) \times(1-\mathrm{p}) / \Delta^{2}$

Where $\mathrm{n}$ is the sample size,

$\mathrm{Z}$ is confidence interval i.e., 1.96 for $95 \%$

$\Delta$ is confidence level i.e., 0.05 for $\pm 5 \%$

$\mathrm{p}=$ prevalence of the event in the population as determined by previous studies.

Taking incidence of fetal acidosis in term singleton pregnancies as per previous studies as $19.4 \%$, sample size for my study is calculated to be:

$\mathrm{n}=(1.96)^{2} \times(0.194) \times(1-0.194) /(0.05)^{2}=240$

For a minimum of 240 women to be included in this study, 301 consecutive women with term singleton gestation in labour were studied

\section{Inclusion criteria}

Women with singleton pregnancy at term (gestational age 37-41 weeks), cephalic presentation and in active labour (cervical dilatation $\geq 4 \mathrm{~cm}$ ) were included in the study.

\section{Exclusion criteria}

Pregnant women with PPROM, PROM, multifetal gestation, malpresentations, congenital anomalies, diagnosed FGR, documented abnormal umbilical Doppler study, antepartum hemorrhage, placental abruption, those undergoing elective caesarean section and women refusing to participate in the study were excluded.

\section{Baseline data recording}

All consecutive women with term singleton pregnancies in labour, fulfilling the inclusion criteria, admitted to our labour ward, over a period of 1 year, were enrolled in the study, after informed consent. On admission, all patients underwent general, systemic and obstetrical examination including evaluation by ultrasound for placental localisation, assessment of liquor and to rule out any fetal compromise. Labour was monitored. Details regarding patient profile, history, gestational age at onset of labour, mode of onset of labour (spontaneous or induced), cervical dilatation on admission, membranes status, time of rupture of membranes (spontaneous or artificial), nature of liquor after rupture of membranes, CTG tracings, mode of delivery, indications for operative delivery, Apgar score at 1 and 5 minutes, nursery stay, baby details, cord blood $\mathrm{pH}$ values were all recorded in study proforma sheets. Intrapartum cardiotocography was done using Philips Avalon FM20 EF Monitor machine. Tracings were taken by the machine at a speed of 3 $\mathrm{cm} / \mathrm{min}$ for 20 minutes. CTG tracings were taken on admission, at rupture of membranes and during active stage of labour every 2 hours till delivery. In case of abnormal fetal heart rate pattern, tracing was repeated after 1 hour for 40 minutes. Fetal heart rate patterns were interpreted using the NICHD classification (ACOG 2013) as per Table $1 .^{2,3}$

\section{Cord blood collection}

Immediately at birth, before the baby's first breath and before delivery of the placenta, the umbilical cord was clamped at two points, $10 \mathrm{~cm}$ apart, with Kocher's clamps and cut. The umbilical artery was immediately identified in the cord and 2-3 $\mathrm{ml}$ of blood was aspirated with a pre-heparinised syringe. To prevent air contact, the syringe tip was sealed with a plastic cover. The blood was delivered to the laboratory within 5 minutes. ${ }^{4}$ Cord blood was analysed by Radiometer ABL 800 Basic Machine used in our institute. The umbilical cord arterial blood $\mathrm{pH}$ was used for assessing fetal acidosis. An umbilical artery $\mathrm{pH}<7.20$ was defined as fetal acidosis. ${ }^{4-6}$ 
Table 1: NICHD classification of CTG tracing (adapted ACOG 2013).

\begin{tabular}{|c|c|c|}
\hline Category & Features & Interpretation \\
\hline \multirow{5}{*}{ I-Normal } & Baseline FHR 110 to $160 \mathrm{bpm}$ & \multirow{5}{*}{$\begin{array}{l}\text { No evidence of fetal hypoxia, } \\
\text { normal acid-base status }\end{array}$} \\
\hline & Baseline variability moderate (6-25 bpm) & \\
\hline & Late or variable decelerations absent & \\
\hline & Early decelerations absent/present & \\
\hline & Accelerations: present or absent & \\
\hline \multirow{15}{*}{ II-Indeterminate } & Includes all FHR tracings not categorised as I and III: & \multirow{15}{*}{ Uncertain fetal status } \\
\hline & Baseline rate & \\
\hline & $\begin{array}{l}\text { Bradycardia (FHR baseline }<110 \mathrm{bpm} \text { ) not accompanied by } \\
\text { absent baseline variability }\end{array}$ & \\
\hline & Tachycardia (FHR baseline $>160$ bpm) & \\
\hline & Baseline FHR variability & \\
\hline & Minimal baseline variability (less than or equal to $5 \mathrm{bpm}$ ) & \\
\hline & $\begin{array}{l}\text { Absent variability (amplitude range undetectable) without } \\
\text { recurrent decelerations }\end{array}$ & \\
\hline & Marked variability (>25bpm) & \\
\hline & Accelerations & \\
\hline & Absence of induced accelerations fetal stimulation & \\
\hline & Periodic or episodic decelerations & \\
\hline & $\begin{array}{l}\text { Recurrent variable decelerations with minimal or moderate } \\
\text { variability }\end{array}$ & \\
\hline & Prolonged deceleration $\geq 2$ minutes but $\leq 10$ minutes & \\
\hline & Recurrent late decelerations with moderate variability & \\
\hline & $\begin{array}{l}\text { Variable decelerations with slow return to baseline, overshoots } \\
\text { or shoulders }\end{array}$ & \\
\hline \multirow{5}{*}{ III-Abnormal } & Absent variability and any of the following & \multirow{5}{*}{ Abnormal acid-base status } \\
\hline & Recurrent late decelerations & \\
\hline & Recurrent variable decelerations & \\
\hline & Bradycardia & \\
\hline & Sinusoidal pattern & \\
\hline
\end{tabular}

Table 2: Interpretation of correlation.

\begin{tabular}{|c|c|}
\hline Correlation coefficient ( $\mathbf{r}$ ) & Interpretation \\
\hline $0-0.3$ & $\begin{array}{l}\text { Positive weak } \\
\text { correlation }\end{array}$ \\
\hline $0.3-0.6$ & $\begin{array}{l}\text { Positive moderate } \\
\text { correlation }\end{array}$ \\
\hline $0.6-1.0$ & $\begin{array}{l}\text { Positive strong } \\
\text { correlation }\end{array}$ \\
\hline 0 to $(-0.3)$ & $\begin{array}{l}\text { Negative weak } \\
\text { correlation }\end{array}$ \\
\hline$(-0.3)$ to $(-0.6)$ & $\begin{array}{l}\text { Negative moderate } \\
\text { correlation }\end{array}$ \\
\hline$(-0.6)$ to $(-1)$ & $\begin{array}{l}\text { Negative strong } \\
\text { correlation }\end{array}$ \\
\hline
\end{tabular}

\section{Statistical analysis}

Data was entered into Microsoft excel data sheet and analysed using SPSS 22 version software. Categorical data was represented in the form of frequencies and proportions. Chi-square was used as test of significance.
Relative Risk or Risk Ratio was calculated to know the risk of abnormal CTG findings with respect to Cord blood $\mathrm{pH}$. $\mathrm{P}$ value $<0.05$ was considered statistically significant.

\section{RESULTS}

On performing intrapartum CTG it was observed that $8 \%$ had bradycardia, $1.3 \%$ had tachycardia, $45.8 \%$ had abnormal beat to beat variability. Of the patients who had abnormal beat-to-beat variability, $10.3 \%$ had absent beatto-beat variability, $34.6 \%$ had minimal beat-to-beat variability $(<5 \mathrm{bpm})$ and $1 \%$ had increased $(>25 \mathrm{bpm})$ variability, $54.2 \%$ had normal beat to beat variability (6 to $25 \mathrm{bpm}$ ). $45.2 \%$ of subjects had no accelerations and $17.9 \%$ of the subjects had decelerations. Of them, $2.7 \%$ had early decelerations, $4 \%$ had late decelerations, $2 \%$ had prolonged decelerations, $9.3 \%$ had variable decelerations. Summarizing, $36.5 \%$ of subjects had Indeterminate (category II) CTG and $13.3 \%$ had Abnormal (category III) CTG findings. Remaining 50.2\% had Normal (category I) CTG. The findings are depicted in Table 3. 
Table 3: Baseline Intrapartum CTG Findings.

\begin{tabular}{|c|c|c|c|}
\hline \multicolumn{2}{|c|}{ Individual features of CTG } & Frequency & Percent \\
\hline \multirow{3}{*}{ Intrapartum FHR } & FHR 110 to 160 Normal & 273 & 90.7 \\
\hline & $<110$ Bradycardia & 24 & 8.0 \\
\hline & $>160$ Tachycardia & 4 & 1.3 \\
\hline \multirow{4}{*}{ Beat to beat variability } & Absent & 31 & 10.3 \\
\hline & Less than 5 (Min) & 104 & 34.6 \\
\hline & 6 to 25 (Moderate) & 163 & 54.2 \\
\hline & $>25$ (Marked) & 3 & 1 \\
\hline \multirow{2}{*}{ Acceleration } & No & 136 & 45.2 \\
\hline & Yes & 165 & 54.8 \\
\hline \multirow{5}{*}{$\begin{array}{l}\text { Deceleration } \\
\text { type }\end{array}$} & None & 247 & 82.1 \\
\hline & Early & 8 & 2.7 \\
\hline & Late & 12 & 4.0 \\
\hline & Prolonged & 6 & 2.0 \\
\hline & Variable & 28 & 9.3 \\
\hline \multirow{3}{*}{ CTG } & Normal (Category I) & 151 & 50.2 \\
\hline & Indeterminate (Category II) & 110 & 36.5 \\
\hline & Abnormal (Category III) & 40 & 13.3 \\
\hline
\end{tabular}

In the study $18.3 \%$ of neonates had acidosis (defined as cord blood $\mathrm{pH}$ <7.2). The mean cord blood $\mathrm{pH}$ was $7.253 \pm 0.07$ (Table 4).

Table 4: Cord blood distribution of neonates.

\begin{tabular}{|llll|}
\hline \multicolumn{1}{|c}{ Cord } & $<7.2$ & Frequency & Percent \\
\cline { 2 - 4 } blood & $\geq 7.2$ & 55 & 18.3 \\
\hline $\mathrm{pH}$ & Total & 246 & 81.7 \\
\hline Mean Cord Blood $\mathrm{pH}$ & 301 & 100.0 \\
\hline Range & $7.253 \pm 0.07$ & \\
\hline Minimum & 0.61 & \\
\hline Maximum & 6.80 & \\
\hline
\end{tabular}

Forty-four babies $(18.3 \%)$ had cord blood $\mathrm{pH}<7.2$ and 257 babies $(81.7 \%$ ) had cord blood $\mathrm{pH} \geq 7.2$. Out of the 151 mothers with normal CTG trace intrapartum, 11 (7.3\%) had acidosis.

Out of the 110 mothers with indeterminate intrapartum CTG, 25 cases $(22.7 \%)$ had acidosis while $85(77.3 \%)$ had normal umbilical artery blood $\mathrm{pH}$.

Of the 40 mothers with abnormal CTG, 21 (52.5\%) had acidosis and $19(47.5 \%)$ babies had normal umbilical artery blood $\mathrm{pH}$. Significant association was found between the type of CTG and umbilical cord artery blood $\mathrm{pH}(\mathrm{p}<0.001)$ as shown in Figure 1.

An abnormal (category III) CTG had a sensitivity of $47.5 \%$ and a specificity of $92.72 \%$ in detecting acidosis. An abnormal CTG had a positive predictive value of $63.33 \%$ and negative predictive value of $86.96 \%$. The overall diagnostic accuracy of an abnormal (category III) CTG in diagnosing fetal acidosis was $83.25 \%$.

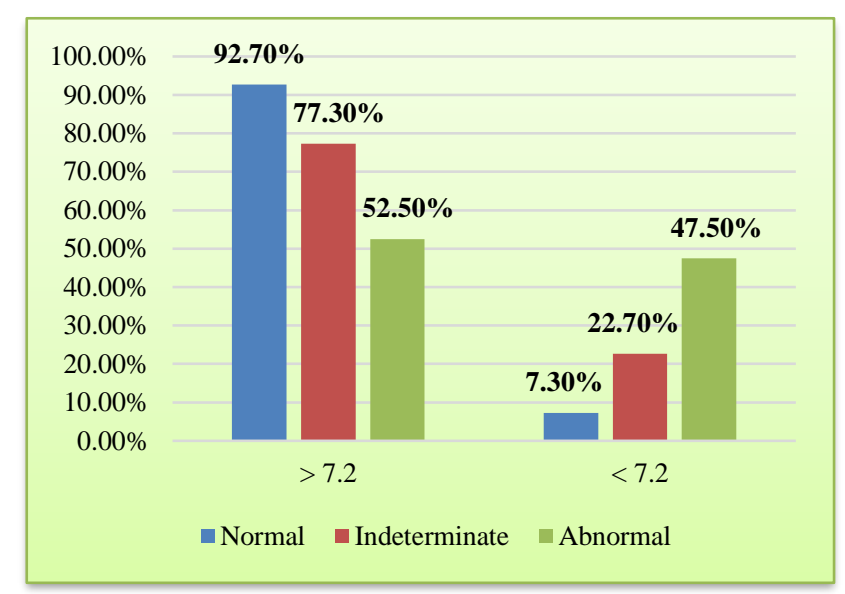

Figure 1: Association between type of CTG and umbilical artery cord blood pH.

Indeterminate (category II) CTG had a sensitivity of $22.73 \%$, specificity of $92.72 \%$, positive predictive value of $69.44 \%$, negative predictive value of $62.22 \%$ and overall diagnostic accuracy of $63.22 \%$. When abnormal (category III) and indeterminate (category II) CTGs were considered together for diagnosis of acidosis, it had a higher sensitivity of $80 \%$, specificity of $56.91 \%$, positive predictive value and negative predictive value of $29.33 \%$ and $92.72 \%$ respectively.

A normal CTG had a sensitivity, specificity, positive predictive value and negative predictive value of $56.91 \%$, $80 \%, 92.72 \%$ and $29.33 \%$ respectively (Table 5). When individual features of CTG were studied, it was found that abnormal FHR had 2.86 times higher risk for abnormal cord blood $\mathrm{pH}$ and bradycardia had 3 times higher risk for abnormal cord blood $\mathrm{pH}$. 
Table 5: Validity of abnormal CTG (category III CTG), indeterminate (category II) CTG and abnormal+indeterminate CTG in diagnosing abnormal cord blood pH (acidosis) and validity of Normal CTG (category III) in diagnosing normal cord blood $\mathrm{pH}$.

\begin{tabular}{|c|c|c|c|c|}
\hline Parameter & $\begin{array}{l}\text { Abnormal } \\
\text { (category III) } \\
\text { CTG }\end{array}$ & $\begin{array}{l}\text { Indeterminate } \\
\text { (category II) } \\
\text { CTG }\end{array}$ & $\begin{array}{l}\text { Abnormal + indeterminate } \\
\text { (category III+category II) } \\
\text { CTG }\end{array}$ & $\begin{array}{l}\text { Normal (category I) } \\
\text { CTG for Normal cord } \\
\text { blood pH }\end{array}$ \\
\hline Sensitivity & $47.5 \%$ & $22.73 \%$ & $80 \%$ & $56.91 \%$ \\
\hline Specificity & $92.72 \%$ & $92.72 \%$ & $56.91 \%$ & $80 \%$ \\
\hline Positive predictive value & $63.33 \%$ & $69.44 \%$ & $29.33 \%$ & $92.72 \%$ \\
\hline $\begin{array}{l}\text { Negative predictive } \\
\text { value }\end{array}$ & $86.96 \%$ & $62.22 \%$ & $92.72 \%$ & $29.33 \%$ \\
\hline Diagnostic accuracy & $83.25 \%$ & $63.22 \%$ & $61.13 \%$ & $61.13 \%$ \\
\hline
\end{tabular}

Table 6: Association between abnormal cord blood PH and individual components of intrapartum CTG findings.

\begin{tabular}{|c|c|c|c|}
\hline Individual components of intrapartum CTG findings & Abnormal cord blood PH & $\mathbf{R R}$ & $95 \%$ CI; P value \\
\hline Baseline FHR & & \multirow{3}{*}{2.167} & \multirow{3}{*}{$\begin{array}{l}1.233 \text { to } 3.809 \\
0.01 *\end{array}$} \\
\hline Abnormal & $10 / 28$ & & \\
\hline Normal & $45 / 273$ & & \\
\hline Baseline FHR & & \multirow{3}{*}{1.517} & \multirow{3}{*}{$\begin{array}{l}0.2721 \text { to } 8.454 \\
\text { NS }\end{array}$} \\
\hline Tachycardia & $1 / 4$ & & \\
\hline Normal & $45 / 273$ & & \\
\hline Baseline FHR & & \multirow{3}{*}{3.011} & \multirow{3}{*}{$\begin{array}{l}1.645 \text { to } 5.51 \\
<0.001 *\end{array}$} \\
\hline Bradycardia & $9 / 24$ & & \\
\hline Normal & $45 / 273$ & & \\
\hline Beat to beat variability & & \multirow{3}{*}{0.4844} & \multirow{3}{*}{$\begin{array}{l}0.30 \text { to } 0.78 \\
0.004^{*}\end{array}$} \\
\hline$<5$ beats & $26 / 104$ & & \\
\hline Normal & $16 / 31$ & & \\
\hline Beat to beat variability & & \multirow{3}{*}{0.154} & \multirow{3}{*}{$\begin{array}{l}0.082 \text { to } 0.288 \\
<0.001^{*}\end{array}$} \\
\hline 6 to 25 beats (moderate) & $13 / 163$ & & \\
\hline Normal & $16 / 31$ & & \\
\hline Beat to beat variability & & \multirow{3}{*}{0.276} & \multirow{3}{*}{$\begin{array}{l}0.02 \text { to } 3.68 \\
0.185\end{array}$} \\
\hline$>25$ (marked) & $0 / 3$ & & \\
\hline Normal & $16 / 31$ & & \\
\hline Acceleration & & \multirow{3}{*}{0.1403} & \multirow{3}{*}{$\begin{array}{l}0.06868,0.2866 \\
<0.001 *\end{array}$} \\
\hline Present & $8 / 165$ & & \\
\hline Absent & $47 / 136$ & & \\
\hline Early decelerations & & \multirow{3}{*}{0.908} & \multirow{3}{*}{$\begin{array}{l}0.141 \text { to } 5.83 \\
0.918\end{array}$} \\
\hline Present & $1 / 8$ & & \\
\hline Normal & $34 / 247$ & & \\
\hline Late decelerations & & \multirow{3}{*}{1.816} & \multirow{3}{*}{$\begin{array}{l}0.649 \text { to } 5.079 \\
0.278\end{array}$} \\
\hline Present & $3 / 12$ & & \\
\hline Normal & $34 / 247$ & & \\
\hline Prolonged decelerations & & \multirow{3}{*}{2.42} & \multirow{3}{*}{$\begin{array}{l}0.748 \text { to } 7.83 \\
0.175\end{array}$} \\
\hline Present & $2 / 6$ & & \\
\hline Normal & $34 / 247$ & & \\
\hline Variable decelerations & & \multirow{3}{*}{2.534} & \multirow{3}{*}{$\begin{array}{l}1.516 \text { to } 4.237 \\
<0.001 *\end{array}$} \\
\hline Present & $15 / 28$ & & \\
\hline Normal & $34 / 247$ & & \\
\hline CTG & & \multirow{3}{*}{3.12} & \multirow{3}{*}{$\begin{array}{l}1.604 \text { to } 6.068 \\
0.0003 *\end{array}$} \\
\hline Indeterminate & $25 / 110$ & & \\
\hline Normal & $11 / 151$ & & \\
\hline CTG & & \multirow{3}{*}{6.52} & \multirow{3}{*}{$\begin{array}{l}3.385 \text { to } 12.56 \\
<0.001 *\end{array}$} \\
\hline Abnormal & $19 / 40$ & & \\
\hline Normal & $11 / 151$ & & \\
\hline
\end{tabular}


Prolonged and variable decelerations had 3.58 and 2.53 times higher risk for abnormal cord blood $\mathrm{PH}$ respectively. On the other hand, a normal FHR variability (6 to $25 \mathrm{bpm}$ ) had lower risk of abnormal cord blood $\mathrm{pH}$ (RR was 0.023). As also presence of accelerations had a lower risk for abnormal cord blood $\mathrm{pH}(\mathrm{RR}=0.1403)$. Indeterminate CTG and abnormal CTG findings had significantly higher risk for abnormal cord blood PH. These observations were statistically significant (Table $6)$.

\section{DISCUSSION}

In this study $50.2 \%$ of the subjects had category I (normal) CTG tracing, 36.5\% had category II (indeterminate) CTG tracing and $13.3 \%$ had category III (abnormal) intrapartum CTG tracing. 90.7\% had normal baseline fetal heart rate, $8.0 \%$ had bradycardia and $1.3 \%$ had tachycardia. This was comparable to the study by Aboulghar $\mathrm{W}$ et al, in this study $82 \%$ had normal baseline fetal heart rate. $^{5}$ However, the incidence of fetal bradycardia- $8.0 \%$ and that of tachycardia-1.3\% was different from the study by Aboulghar W which had a higher incidence of fetal tachycardia (17\%). ${ }^{5}$ This difference can be explained by the fact that the study by Aboulghar W had included cases with PROM, which might have been the cause of fetal tachycardia. ${ }^{5}$ In present study, cases with PROM were excluded.

In the present study, $45.8 \%$ had abnormal beat-to-beat variability $(34.6 \%$ cases had minimal variability, $10.3 \%$ had absent variability and $1 \%$ had increased variability). This value of abnormal FHR variability on CTG is slightly less than that in a study by $\mathrm{W}$ Aboulghar ${ }^{5}$ et al, where abnormal FHR variability was found to be $55 \% .^{5}$ In the present study, accelerations on CTG were present in $54.8 \%$ cases whereas in the study by $\mathrm{W}_{\text {Aboulghar }}^{5}$ et al, accelerations were present in $6 \%$ cases. ${ }^{5}$ Decelerations on CTG were present in $17.9 \%$ cases in the present study, which is comparable to the study by Modarressnejad V, who studied prospectively 400 consecutive term gestations, where $14.25 \%$ of the subjects had decelerations. $^{7}$ In the study by Aboulghar $\mathrm{W}$ et al, decelerations were present in $53 \%$ cases. ${ }^{5}$ This difference could be due to the fact that in the present study consecutive women in labour have been included, whereas Aboulghar W et al studied 100 women who underwent caesarean section for pathological or suspicious $\mathrm{CTG}^{5}$

In the present study, mean cord blood $\mathrm{pH}$ was $7.253 \pm$ 0.07. This is comparable to several studies. ${ }^{4-7}$ Kaban et al used the cut off value for defining acidosis as cord blood $\mathrm{pH}<7.2$ in their study. ${ }^{4}$ Modarressnejad V defined fetal acidosis as cord blood $\mathrm{pH}<7.1$. $^{7}$ In the present study, an umbilical arterial cord blood $\mathrm{pH}$ of $<7.2$ at birth is taken as the cut-off value to define acidosis in the neonate. $18.3 \%$ of the neonates had acidosis which is comparable to the studies by $\mathrm{Kaban}^{4}$ et al (13.26\%) and Modarressnejad V (20.25\%). ${ }^{4,7}$ In the study by Aboulghar
W et al, incidence of acidosis was higher, with $34 \%$ of babies having abnormal cord blood $\mathrm{pH}$. This higher value of acidosis in the neonates could be explained by the fact that their study included only those women who had undergone caesarean section for pathological and suspicious CTG, while in the other studies mentioned above and in our study, consecutive term labouring women were included.

Jackson et al studied the intrapartum fetal heart rate (FHR) characteristics of over 48,000 patients with a singleton, non-anomalous fetus in term labor at 10 hospitals. ${ }^{8}$ In their study, considering all of labor, the FHR pattern was category I in 77.9 percent of the time, category II 22.1 percent of the time and category III 0.004 percent of the time. In the two hours before delivery, category I tracings were less commonly observed $(60.9 \%)$ and both category II and category III tracings became more common $(39.1 \%$ and $0.006 \%$, respectively). They concluded that category I and II fetal heart rate patterns are more common in labour than category III. Results from the present study are comparable with this finding.

In this study, $52.5 \%$ of the cases with category III (abnormal) CTG had acidosis and $22.7 \%$ cases with category II (indeterminate) CTG had acidosis (Figure 2). Only $7.3 \%$ of the subjects with category I (normal) CTG had acidosis. A significant association was found between the type of CTG and cord blood $\mathrm{pH}$. Also, there was an increased risk of having abnormal cord blood $\mathrm{pH}$ with an abnormal CTG. These values are comparable with the study by Aboulghar W et al, where $50 \%$ of cases with pathological CTG had acidosis and $19.2 \%$ of cases with suspicious CTG had acidosis. ${ }^{5}$ They also found that pathological (rather than suspicious) CTG significantly increased the risk of abnormal cord blood $\mathrm{pH}$. Findings of the present study are also comparable to study by Kaban et al who studied 101 term pregnant women admitted for delivery. ${ }^{4}$ In their study 85 neonates had normal cord arterial $\mathrm{pH}$ and 13 had fetal acidosis as diagnosed by cord arterial $\mathrm{pH}$ values $<7.2$. Of the 13 neonates with acidosis, 5 had non-reactive CTG tracings intrapartum. All the 85 neonates without acidosis had reactive CTG tracings.

In the present study, it was found that abnormal FHR had 2.86 times higher risk for abnormal cord blood $\mathrm{pH}$ and bradycardia had 3.011 times higher risk for abnormal cord blood $\mathrm{pH}$. There was significantly lower risk of having an abnormal cord blood $\mathrm{pH}$ in cases where CTG showed normal beat-to-beat variability (between 6-25 bpm). Prolonged and variable decelerations had higher risks for abnormal cord blood $\mathrm{pH}$. Indeterminate and abnormal CTG had significantly higher risk for abnormal cord blood $\mathrm{pH}$ (Table 6). In the study by Aboulghar $\mathrm{W}$ et al, analysis of different features of CTG as predictor of abnormal cord blood $\mathrm{pH}(<7.2)$ showed that bradycardia significantly increased the risk for abnormal cord blood $\mathrm{pH}$ by almost 3 times, which is similar to this study. ${ }^{5}$ They also found that abnormal beat-to beat variability, 
late deceleration and variable deceleration significantly increased the risk of abnormal cord blood $\mathrm{pH}$. They concluded that pathological (rather than suspicious) CTG significantly increased the risk of abnormal cord blood $\mathrm{pH}$. Findings of this study are comparable to theirs.

An abnormal (category III) CTG had sensitivity of $47.5 \%$ and specificity of $92.72 \%$ in detecting acidosis (Table 5), which meant that while an abnormal (category III) CTG tracing could detect $47.5 \%$ of subjects with acidosis, it had a good ability to identify those who did not have acidosis because of its high specificity. It was also found that an abnormal CTG had a positive predictive value of $63.33 \%$ and negative predictive value of $86.96 \%$, which meant that in absence of an abnormal CTG, the chance of having acidosis was very little. The overall diagnostic accuracy of an abnormal (category III) CTG in diagnosing fetal acidosis was $83.25 \%$. This study also found that an indeterminate (category II) CTG had sensitivity of $22.73 \%$ and specificity of $92.72 \%$ in detecting acidosis, which meant that an indeterminate CTG could diagnose only $22.72 \%$ of subjects who had acidosis. However, from its high specificity, it also had a good ability to identify those who did not have acidosis.

However, when abnormal (category III) and indeterminate (category II) CTG were taken together to diagnose acidosis, they were shown to have a higher specificity of $80 \%$ in detecting acidosis. Specificity of both abnormal and indeterminate CTG in detecting acidosis was $56.91 \%$. Positive predictive value and negative predictive value of abnormal+indeterminate CTG were $29.33 \%$ and $92.72 \%$ respectively. It meant that in the absence of an abnormal or an indeterminate CTG, there was very less chance of having a fetus with acidosis. The present study also found that a normal CTG had a sensitivity, specificity, positive predictive value and negative predictive value of $56.91 \%, 80 \%, 92.72 \%$ and $29.33 \%$ respectively, for diagnosing normal cord blood $\mathrm{pH}$. This meant that a normal CTG can accurately detect babies without acidosis, that is, in presence of a normal CTG, there was minor possibility of fetus having acidosis. These findings are comparable with those found by Parveen who concluded that a normal CTG trace correlates highly with absence of fetal acidosis. ${ }^{9}$ Parveen studied 122 cord blood samples were using umbilical cord arterial base excess $(>12 \mathrm{mmol} / \mathrm{l})$ at birth to diagnose fetal acidemia. ${ }^{9}$ From their study they found that cardiotocography has a sensitivity of $15.38 \%$, specificity of $86 \%$, positive predictive value $11.76 \%$ and a negative predictive value $89 \%$. This difference may be because of the fact that they took umbilical artery base excess at birth to diagnose fetal acidosis, while in the present study, umbilical cord arterial $\mathrm{pH}$ value of $<7.2$ was taken to diagnose fetal acidosis.

Visser et al who studied normal and abnormal patterns of CTG tracings and correlated CTG findings with fetal distress after birth by umbilical cord blood gas analysis and found sensitivity, specificity, positive predictive value and negative predictive value of CTG to be $79 \%$, $85 \%, 68 \%$ and $91 \%$ respectively. ${ }^{10}$ Steer PJ et al conducted a prospective study to find correlation among FHR patterns, MSL, umbilical cord arterial blood $\mathrm{pH}$ and Apgar score in 698 cases and found that sensitivity of an abnormal CTG at any time for fetal acidosis (cord arterial $\mathrm{pH}<7.17$ ) was $80 \%$ and for severe acidosis $(\mathrm{pH}<7.08)$ was $83 \% .{ }^{11}$ However positive predictive value was low: $32 \%$ foetuses had abnormal CTG but no acidosis. If only CTG abnormality in $1^{\text {st }}$ stage labour was considered sensitivity was $47 \%$ for acidosis \& $67 \%$ for severe acidosis and false positive was $14 \%$. In a study by Tasnim et al, positive predictive value of CTG was $18 \%$ for fetal hypoxia, $21 \%$ for fetal hypercarbia, $26 \%$ for fetal acidosis and $37 \%$ for base excess. ${ }^{12}$ Predictive value of suspicious trace for similar blood indices was $13 \%, 13 \%$, $17 \%$ and $35 \%$ respectively. For pathological trace, predictive value was $50 \%, 83 \%, 100 \%$ and $66 \%$ and respectively. They concluded that suspicious CTG trace has low predictive value in terms of fetal acid base status at birth and needs to be complemented with other diagnostic modalities before undertaking any operative intervention. Pathological CTG on the other hand is highly predictive of fetal acidosis at birth warranting immediate intervention.

Thus, from the findings of the present study, although the sensitivity of CTG was found to be low, its high specificity, low cost and ease of carrying out the monitoring supported its use in intrapartum fetal monitoring and in alerting the obstetrician regarding an intra-uterine hypoxic event.

\section{CONCLUSION}

The fetus undergoes physiological stress during labour. Fetal morbidity and mortality may occur as a consequence of labour even in low risk patients. Cardiotocography is a simple, noninvasive recordable method of intrapartum fetal monitoring which can be used as a tool to detect hypoxaemic event in the fetus-inutero during labour, enabling initiation of appropriate management. We studied the correlation between intrapartum CTG in term labouring women with cord blood $\mathrm{pH}$ in their neonates in order to predict acidosis in the fetus. From the findings of this study, we can conclude that in presence of an abnormal or indeterminate CTG, there is higher possibility of intrapartum fetal acidosis while presence of a normal CTG indicates a minor possibility of intrapartum fetal acidosis. There is high risk of acidosis when findings of bradycardia, loss of beat-to-beat variability, prolonged and variable decelerations were present in CTG during labour. Presence of a normal beat-to-beat variability (between 6-25 bpm) is reassuring.

Thus, CTG is a simple test, easy to perform and can alert the obstetrician for necessary interventions in case of an abnormal CTG. It can detect fetal distress in labour, thus helping to reduce neonatal morbidity by early 
intervention in cases of abnormal tracings. From the analysis of this study, it can be concluded that an abnormal CTG should be managed appropriately, without any delay, in order to prevent acidosis in the neonate and adverse long-term sequelae. The obstetrician should be more vigilant in cases of indeterminate CTG tracings and monitor such labours closely.

\section{ACKNOWLEDGMENTS}

Authors would like to thank Dr. Manas Kabiraj, Senior Specialist and Head of the Department and Dr Alokananda Ray, Senior Consultant, Department of Obstetrics and Gynaecology, Tata Main Hospital, Jamshedpur for their constant guidance and constructive advice during this work.

Funding: No funding sources

Conflict of interest: None declared

Ethical approval: The study was approved by the Institutional Ethics Committee

\section{REFERENCES}

1. MacLennan A. A template for defining a causal relationship between acute intrapartum events and cerebral palsy. In: Bonnar J, ed. By. Recent advances in Obstet Gynaecol. Churchill Livivngstone; 2001(21):86-93.

2. Macones G, Hankins G, Spong C, Hauth J, Moore T. The 2008 National Institute of Child Health and Human Development workshop report on electronic fetal monitoring: update on definitions, interpretation and research guidelines. Obstet Gynecol. 2008;112(3):661.

3. Macones GA. Intrapartum fetal heart rate monitoring: nomenclature, interpretation, and general management principles. Obstet Gynecol. 2009;114(1):192-202.

4. Kaban A, Cengiz H, Kaban I, Özcan A, Karakaş S. The success of cardiotocography in predicting perinatal outcome. J Clini Experiment Investigations. 2012;3(2):168-171.

5. Aboulghar WM, Ibrahim MA, Allam IS, Hosny W, Otify M. Validity of cardiotocography in the diagnosis of acute fetal hypoxia in low resources settings. Internet J Gynecol Obstet. 2013;17(1):1-8.

6. Yeh P, Emary K, Impey L. The relationship between umbilical cord arterial $\mathrm{pH}$ and serious adverse neonatal outcome: analysis of 51519 consecutive validated samples. BJOG. 2012;119:824-831

7. Modarressnejad V. Umbilical cord blood $\mathrm{pH}$ and risk factors for acidaemia in neonates. Eastern Mediterranean Health J. 2005;11(1/2):96-101.

8. Jackson M, Holmgren CM, Esplin MS, Henry E, Varner MW. Frequency of fetal heart rate categories and short term neonatal outcome. Obstet Gynecol. 2011;118(4):803-8.

9. Parveen S. Umbilical cord arterial blood base excess as gold standard for fetal wellbeing screening test at term delivery. JMPA. 2010;60(5):347-350.

10. Visser GHA, Sadovsky G, Nicolaides KH. Antepartum fetal heart rate patterns in small for gestational age third trimester foetuses: correlations with blood gas values obtained at cordocentesis. Am J Obstet Gynecol. 1990;162(3):698-703.

11. Steer PJ, Eigbe F, Lissauer TJ, Beard RW. Interrelationships among abnormal cardiotocograms in labor, meconium staining of the amniotic fluid, arterial cord blood $\mathrm{pH}$ and Apgar scores. Obstet Gynecol. 1989;74(5):715-21.

12. Tasnim N, Mahmud G, Akram S. Predictive accuracy of intrapartum cardiotocography in terms of fetal acid base status at birth. J Coll Physicians Surg Pak. 2001;19(10):632-5.

Cite this article as: Ray C, Ray A. Intrapartum cardiotocography and its correlation with umbilical cord blood $\mathrm{pH}$ in term pregnancies: a prospective study. Int J Reprod Contracept Obstet Gynecol 2017;6:2745-52. 